\title{
Dissociative Symptoms and Reported Trauma Among Patients with Spirit Possession and Matched Healthy Controls in Uganda
}

\author{
Marjolein van Duijl • Ellert Nijenhuis • \\ Ivan H. Komproe • Hajo B. P. E. Gernaat • \\ Joop T. de Jong
}

Published online: 17 April 2010

(C) The Author(s) 2010. This article is published with open access at Springerlink.com

\begin{abstract}
Spirit possession is a common, worldwide phenomenon with dissociative features. Studies in Europe and the United States have revealed associations among psychoform and somatoform dissociation and (reported) potential traumatic events. The aim of this study was to explore the relationships among spirit possession, dissociative symptoms and reported potentially traumatizing events in Uganda. One hundred nineteen persons with spirit possession, diagnosed by traditional healers, were compared to a matched control group of 71 nonpossessed
\end{abstract}

M. van Duij1

Clinic for Refugees at Center 45, Oegstgeest, The Netherlands

M. van Duijl

Foundation Arq Psychotrauma Research, Diemen, The Netherlands

E. Nijenhuis

Top Referent Trauma Center GGZ Drenthe, Assen, The Netherlands

I. H. Komproe

HealthNet TPO, Amsterdam, The Netherlands

I. H. Komproe

Faculty of Social and Behavioral Sciences, Utrecht University, Utrecht, The Netherlands

H. B. P. E. Gernaat

Department of Psychiatry, Diaconessenhuis, Meppel, The Netherlands

J. T. de Jong

Cultural and International Psychiatry, VU University, Amsterdam, The Netherlands

J. T. de Jong

Department of Psychiatry, Boston University School of Medicine, Boston, MA, USA

M. van Duijl $(\bowtie)$

Center 45, Rijnzichtweg 35, 2342 AX Oegstgeest, The Netherlands

e-mail: marjolein.vanduijl@planet.nl 
persons. Assessments included demographic items and measures of dissociation and potentially traumatizing events. Compared to the nonpossessed group, the possessed group reported more severe psychoform dissociation and somatoform dissociation and more potentially traumatizing events. The associations between these events and both types of dissociation were significant. Yet, consistent with the cultural perception of dissociative symptoms, the participants subjectively did not associate dissociative symptoms with potentially traumatizing events. In conclusion, spirit possession deserves more interest as a possible idiom of distress and a culturespecific expression of dissociation related to potential traumatizing events.

Keywords Spirit possession - Traumatic experiences - Idioms of distress · Dissociative trance disorder - Uganda

\section{Introduction}

Spirit possession is a common dissociative phenomenon, manifesting not only in African, Asian and Caribbean countries but also in Europe and North America (Bourguignon 1973, 1976; Behrend and Luig 1999). It receives little attention from mental health care systems, possibly due to the cultural complexity of defining pathological trance syndromes and its diagnosis and treatment (Cardeña et al. 2008; Castillo 1992, 1998). Distinction between normal dissociative trance and possession states, for example, as part of cultural or religious rituals, and pathological trance and possession states bringing distress and impairment in functioning has been an important debate preceding inclusion of experimental criteria for possessive trance disorder and dissociative trance disorder (DTD) in the DSM-IV.

Studies in Europe and the United States revealed associations among dissociation and reported events that are potentially traumatizing. Although trauma-related disorders among refugees and people in postconflict areas receive increasing interest (e.g., De Jong 2002; De Jong et al. 2001, 2003), there is still little research on the relationship between potentially traumatizing events and idioms of distress such as spirit possession. In Uganda, dissociative behavior is culturally sanctioned and often elicited during certain rituals (Van Duijl et al. 2005; Welbourn 1964). Because the country has been haunted by collective violence (Krug et al. 2002), one might also expect an increase in dissociative presentations (Van Ommeren et al. 2001) related to traumatic experiences. In the present study, the relationships among spirit possession, dissociative symptoms and reported potentially traumatizing events in Uganda were explored.

This paper includes the following steps: the "Background" section describes spirit possession as a dissociative manifestation in Uganda, the relationship between dissociation and trauma in other, mainly Western, countries and the need for quantitative research on the relationship between spirit possession and traumatic experiences. Uganda presents an interesting venue in which to investigate this relationship, because spirit possession is deeply imbedded in the traditional mythology and cultural practices and interacts with the multiple stressors of a prolonged civil war.

The "Methods" section describes the context, participants and procedure, instruments and statistical methods used for this study. In "Results" and 
"Discussion" sections our hypotheses on attributions of spirit possession, the relationships between spirit possession and dissociative symptoms, spirit possession and potentially traumatizing events and dissociation and reported potentially traumatizing events in Uganda are presented and discussed. Finally, implications for clinical practice, classification and research are discussed.

\section{Background}

Spirit Possession in Uganda

Dissociation in Uganda is common and often understood in spiritual terms as spirit possession (Van Duijl et al. 2005). Although spirit possession is also used as an explanation for various physical and psychological symptoms, in this paper we refer to local presentations of dissociative and possessive trance in Uganda (cf. Van Duijl et al. 2005). In Runyankore, the local language spoken by the Banyankore of Southwestern Uganda where the research was carried out, various terms are used to describe spirit possession. These are Okutembwa, meaning possession by (evil) spirits, including talking with another voice; Okutembwa Ekikooto or Ekikooto, meaning (evil) spirits (Отизити in Runyankole; these spirits talk in their language of origin when they present); and Okugwa, meaning shaking and falling down. A possession trance state is often named by specific types of spirits and powers such as Emizimu, Ndahura, Nyabingi, Kahumpuri, Nyabirezi, Munonga and Bachwezi. The manifestations depend on the characteristics of the possessing agent. The local categories are based on the different types of spirits (Emuzimu), gods (Bachwezi) and messengers (Emandwa). With the coming of Christianity, some were referred to as evil spirits: Ekyakgo/Ebyako (Van Duijl et al. 2005). Welbourn (1964) describes similarly how in the past these spirits were an accepted part of the normal social context grounded in the mythology on the origins of the former Ankole kingdom and its tribes. Until it was driven underground by both government and mission, the Emandwa cult was part of daily life, with rituals and offerings to assure the support of the Emandwa for wellbeing, safety and a high agricultural yield. Emuzimu, often representing fathers, uncles and other elders and ancestors of the family, could punish bad actions and bring misfortune. Healers (Omuraguzi) will make the diagnosis of underlying trouble, using material means such as a grasshopper, seeds, cowry shells or the guts of a chicken for their divination. Others use dissociation and possession into a particular type of Emandwa to identify problems and negotiate on offerings and rituals to appease the spirits next to the use of (herbal) medicines.

\section{Dissociation and Trauma}

In many cultural settings, dissociative phenomena are experienced as part of the normal cultural construction of self, local cosmology and society. However, in Western psychology and psychiatry, dissociation is mostly treated as pathological and associated with traumatic experiences (Seligman and Kirmayer 2008). Although some have disputed the relationship between dissociative symptoms and traumatic 
experiences, others have confirmed the association between traumatic exposure and dissociative symptoms and disorders in various settings (Lewis-Fernández et al. 2007). Retrospective studies in Western countries suggested a relationship between psychoform and somatoform manifestations of dissociation and recalled potentially traumatizing events (Boon and Draijer 1995; Chu et al. 1999; Nijenhuis et al. 1998b, 2004; Putnam 1992; Van der Kolk et al. 1996). Retrospective studies in other countries such as Turkey (Sar et al. 2000; Sar 2006) and among Bhutanese refugees in Nepal (Van Ommeren et al. 2001, 2003) also found that individuals reporting overwhelming events had more dissociative symptoms than controls. Several authors concluded that potentially traumatizing events can be predictors of dissociative symptomatology, particularly when the events are severe and recurrent, when they involve threats to the body from a person or betrayal and when they involve an individual who is young or who was previously traumatized (Chu et al. 1999; Freyd 1996; Nijenhuis et al. 1998c; Van der Kolk et al. 1996). Other authors doubt the veracity of the reported traumas (Brown 1995; Loftus 1993). However, prospective and longitudinal studies of the relationship have found causal associations between documented traumatization and dissociative symptoms (Diseth 2006; Lyons-Ruth and Jacobovitz 1999; Macfie et al. 2001; Ogawa et al. 1997).

\section{Spirit Possession and Trauma}

In anthropological studies, spirit possession has been described as occurring more frequently among marginal, subordinate and underprivileged people (O'Connel 1982) and has been regarded as a response to intrapsychic tension, difficulties with relatives and situations associated with low expectations for aid and support (Ward 1980) or socioeconomic change (De Jong 1987). Castillo (1994a, b) suggested that trauma was a risk factor for spirit possession in South Asia. Ng and Chan (2004) found that common stressors for DTD in Singapore include problems with military life, conflicts over religious and cultural issues, and domestic disharmony and marital woes. Van Ommeren et al. (2001) identified trauma, early loss and recent loss as predictors of attacks of medically unexplained illness in a Bhutanese refugee camp. This involved alterations of consciousness, which were attributed to possession by spirits, rather than to traumatic experiences. However, we should be careful as to our cultural bias, in terms of defining events as potentially traumatizing. Experiences attributed to angry ancestral spirits could pose a stronger threat to one's physical integrity of self or others than the items in the HTQ and TEC (De Jong 2004). Despite the large anthropological literature documenting the social function of spirit possession in different cultures, there is hardly any systematic, quantitative research investigating the relationship between spirit possession and potentially traumatizing events.

\section{Aims of This Study}

The purpose of this study was to explore the associations among spirit possession, dissociative symptoms and reported potentially traumatizing events in Uganda. The study tested the following hypotheses: (1) participants do not attribute their 
possessed states to traumatic experiences; (2) compared to controls, respondents with spirit possession report more psychoform and somatoform dissociative symptoms; (3) compared to controls, respondents with spirit possession report more potentially traumatizing events; and (4) psychoform and somatoform dissociation are associated with reporting potentially traumatizing events.

\section{Methods}

\section{Context of the Study}

This study was conducted in Uganda, where the population has suffered from war under past dictators and current rebel groups, the AIDS crisis, other infectious diseases and poverty. In this sense, Uganda is a particularly interesting context in which to study the impact of traumatic experiences, given the history of civil war and other major stressors. The psychosocial impact of traumatic experiences in Uganda has been well documented (Derluyn et al. 2004; Musisi 1998; Van Duijl 2003; Vinck et al. 2007). Despite the slowly increasing attention to this impact from the government and nongovernmental organizations, accessibility of mental health and psychosocial services in most of the country remains extremely limited. Most people therefore depend on traditional healers and churches for psychological relief. This can explain the role of spirit possession as an idiom of distress in a context where there has been a lot of potential trauma, and maybe there still are not a lot of sanctioned avenues for expression of these traumatic experiences other than through cultural and religious channels.

The particular area of study comprises the districts Mbarara, Bushenyi and Ntungamo, in southwestern Uganda. These districts were part of the former kingdom of Ankole, which was abolished by the former dictator Milton Obote in 1967 (Wikipedia). Dictator Idi Amin divided the area into the current districts. Most people live in rural areas and the economy depends mainly on agriculture (crops and livestock), mostly on the subsistence level.

The first author of this paper was involved in developing public mental health services in this area while serving as Head of the Department of Psychiatry at Mbarara University for five and a half years (Van Duijl 2003). With her Ugandan colleagues in the department, she met with traditional healers on a regular basis and gradually gained their trust. During the qualitative research preceding this study, focus-group discussions with traditional healers, religious leaders, health workers and medical students revealed that possessive trance disorders were not generally seen as being induced by psychologically traumatizing events but were attributed to beliefs about disappointed (ancestral) spirits and magical-religious manipulations such as witchcraft and sorcery (Van Duijl et al. 2005). However, clinical experience at the mental health clinic suggested that severe psychological stressors also played a role in this condition. A common issue in the history of female patients presenting with spirit possession, which we classified as DTDs, was forced separation from a child or loved one. The following case serves as an example. 
A 33-year-old woman came to our mental health clinic accompanied by her sister. For many years she had regularly suffered from attacks in which, according to her sister, she displayed aggressive and strange behavior, after which she started talking in different voices, which were not recognized as her own.

These attacks occurred when the family prepared to go to Christian church or to say prayers. During our session, the client shifted into a trancelike state, and started to move her hands like claws and made animal-like noises, after which she began to speak in a strange language and voice. Her sister explained that this was the voice of an uncle who had died many years ago. This uncle still valued traditional cultural beliefs, while their father had turned to Christianity. There had been an unsolved conflict between their father and this uncle as their father refused to perform rituals for the ancestors.

Later during our conversation one leg of the client made involuntary shaking movements. This was distracting the client's attention. I asked her what her leg was trying to tell us. By bits and pieces the history became clear: The client had been in love for many years with a Muslim man, with whom she had a child. Her father despised the man because of his religion, and her child was forcefully separated from her by her father.

The church attributed her attacks of possession trance states to activities of "the devil." She had participated in prayer sessions to get rid of these attacks but it had only helped for a short period. We suspected that her attacks, which often occurred when religious activities were performed, were an expression of suppressed anger against her Christian father who had ruined her life because of his rigid principles. Different options for treatment were discussed including traditional healers, counseling and prayer sessions. Although we regularly discussed and referred our patients to traditional healers, in this case the patient preferred to attend counseling sessions to learn to control her attacks and to focus attention on the underlying experience of traumatic loss.

Participants and Procedure

By using key informants, inventory lists were made of traditional healers (approximately 80) in the area of the research. Those reported to offer treatment to patients suffering from spirit possession (19 healing places) were approached and asked to refer patients they had assessed as suffering from possession by a spirit or power or as the result of witchcraft or sorcery by another person. Referred patients ( $n=119)$ were interviewed at the healer's place on a next visit.

The control group, consisting of nonpossessed mentally healthy persons $(n=71)$, was derived from the same villages. By cluster sampling, the first adult person found in every third dwelling was approached. Individuals with a history of mental illness or spirit possession were excluded. All participants gave verbal consent and procedures were in accordance with the Helsinki Declaration (World Medical Assembly 1997). Study and procedures were approved by the International Research Review Board of Mbarara University and the District Authorities. A 
Ugandan research assistant interviewed all individuals in the local language (Runyankore) under supervision of the first author.

A case-control study was carried out to explore the hypotheses on the relationships among spirit possession, dissociative symptoms and reported potentially traumatizing events in Uganda with the instruments described below.

\section{Instruments}

The Spirit Possession Questionnaire-Uganda (SPQ-Ug) was locally designed to cover the main demographics of the respondents and included open-ended questions inquiring about psychosocial stressors, characteristics of the possession and participants' history and subjective explanation of their possession. An adjusted version was used for controls. To exclude people who had suffered from possession trance or from a mental illness, the questionnaire started with three questions inquiring whether respondents had suffered from states of spirit possession with shaking of the body and speaking in a different voice, had experienced a mental illness or had received treatment for mental illness. Furthermore, items inquiring about symptoms of the possession trance state were replaced with items covering general health complaints in the preceding year.

The Checklist Dissociative Symptoms for Uganda (CDS-Ug) is a locally designed, seven-item checklist based on information obtained in focus-group discussions with traditional healers, religious leaders, various health professionals and community members (Van Duijl et al. 2005) It covers locally described symptoms of dissociation and spirit possession that were reported to be common and typical, such as amnesia, shaking of the body, talking in a different voice, fugues, feeling that something is holding the body, exhibiting a sudden change in behavior and speaking in tongues. The internal consistency of the CDS-Ug was excellent, with a Cronbach's $\alpha=0.98$. This instrument was also used to confirm the healers' diagnoses of spirit possession in the case group.

The Dissociative Experiences Scale (DES; Bernstein and Putnam 1986) is a 28-item self-report questionnaire that evaluates psychoform dissociation such as having no memory of certain events, not knowing how one reached a certain place and experiencing the surrounding as unreal. The scores range from 0 (never) to 100 (always). The DES showed adequate test-retest reliability, good internal consistency and good clinical validity (Carlson et al. 1993; Frischholz et al. 1992). Cronbach's $\alpha$ of the DES in the current sample in Uganda was 0.94.

The Somatoform Dissociation Questionnaire (SDQ-20; Nijenhuis et al. 1996, $1998 \mathrm{a}, 1999$ ) is a 20-item self-report questionnaire measuring somatoform manifestations of dissociation such as analgesia ("insensitive to pain"), motor inhibitions ("feeling paralyzed," "unable to speak," "cannot hear") and pain sensations ("pain while urinating"). The high intercorrelation with measures of psychoform dissociation support the convergent validity of the SDQ-20 (Nijenhuis et al. 1996, 1998a; Sar et al. 2000). Validity and reliability are high in the western European context. Cronbach's $\alpha$ of the SDQ in the present sample in Uganda was 0.80 .

The Harvard Trauma Questionnaire (HTQ; Mollica et al. 1992), part 1, covers potentially traumatizing events such as lack of food and water, lack of shelter and 
medical access, being close to death, forced separation, war experiences, torture, serious injury, being lost or kidnapped, being imprisoned and rape. The HTQ is widely used and has face validity with respect to refugee trauma and postconflict areas in developing countries (Crescenzi et al. 2002; De Jong et al. 2001, 2003; Sabin et al. 2003).

The Traumatic Experiences Checklist (TEC; Nijenhuis et al. 2002) is a selfreport questionnaire inquiring about potentially traumatizing events such as loss of significant others, life threat by disease or assault and war experience. The internal consistency, test-retest reliability, convergent validity and criterion-related validity of the TEC were quite satisfactory in a Dutch sample of psychiatric patients (Nijenhuis et al. 2002). We included the TEC, next to the HTQ, as a second measure of potentially traumatic events, in order to compare our results with past research on the relationship of dissociation and trauma.

\section{Translation Process}

The questionnaires were translated from English to Runyankore by three independent bilingual mental health professionals and back-translated to English by three other bilingual mental health professionals. Final versions were agreed on in focus-group discussions. Because of the high illiteracy rate among the participants, all questionnaires were administered verbally by the research assistant.

\section{Statistical Analysis}

Demographics of the case and control groups were compared with $\chi^{2}$ and $t$-tests. Responses of the case group to open-ended questions about the perceived cause of the spirit possession and the outcome of the healing process were categorized and percentages were calculated. Mean scores of both groups on the CDS-Ug were compared as a validity check on the locally used inclusion and exclusion criteria on "spirit possession." The relationship between spirit possession and dissociative symptoms was initially explored by comparing the mean scores of case and control group on the DES and the SDQ-20 and correlations between the CDS-Ug and the DES/SDQ-20.

The relationship between spirit possession and reported potentially traumatizing events measured by the HTQ and TEC was evaluated by comparing the total number of reported potentially traumatizing events of both groups with a $t$-test. In addition, frequencies of events were compared with $\chi^{2}$ tests.

The relationships among psychoform dissociation, somatoform dissociation and reported potentially traumatizing events were analyzed by calculation of Pearson correlations. Multivariate analysis of variance (MANOVA) was applied to test whether the general profile of dissociative symptoms (scores on SDQ and DES) differed between the possessed and the nonpossessed groups. Reported potentially traumatizing events on the TEC were defined as a covariate to correct for spurious effects (e.g., difference between groups with respect to experienced events and 
relationship between events and dissociative symptoms). Wilks' $\lambda$ was the criterion for the multivariate evaluation. $F$-tests were used to evaluate the different subscales. The results of the multivariate tests were checked for violations of assumptions to use MANOVA. Because the distributions of the DES, SDQ-20 and trauma questionnaire scores were skewed (skewness $>1$ ), logarithmic transformations to base $e$ of these measurements were performed. Outlying cases $(n=6)$ were removed based on scatter plot analyses per group for the interactions between DES/ TEC and SDQ-20/TEC. The statistical analyses were performed with SPSS-PC 11 (Norusis 2002), and $p$-values $<0.05$ were considered statistically significant.

\section{Results}

Demographics

Table 1 shows that the case and control group were similar in terms of main demographic characteristics.

Table 1 Main demographics of patients with spirit possession $(n=119)$ and controls $(n=71)$, southwestern Uganda

\begin{tabular}{|c|c|c|c|c|c|c|c|c|}
\hline \multirow[t]{2}{*}{ Variable } & \multirow[t]{2}{*}{ Subcategory } & \multicolumn{2}{|c|}{ Spirit possession } & \multicolumn{2}{|c|}{ Controls } & \multirow[t]{2}{*}{$\chi^{2}$} & \multirow[t]{2}{*}{$\mathrm{df}$} & \multirow[t]{2}{*}{$p$} \\
\hline & & $N$ & $\%$ & $N$ & $\%$ & & & \\
\hline \multirow[t]{2}{*}{ Gender } & Male & 53 & 44.5 & 35 & 49.7 & 0.561 & 1 & 0.454 \\
\hline & Female & 66 & 55.5 & 36 & 50.3 & & & \\
\hline \multirow[t]{5}{*}{ Marital status } & Married & 80 & 67.8 & 46 & 64.8 & 1.258 & 4 & 0.868 \\
\hline & Unmarried & 16 & 13.6 & 10 & 14.1 & & & \\
\hline & Separated & 9 & 7.5 & 8 & 11.3 & & & \\
\hline & Divorced & 2 & 1.7 & 2 & 2.8 & & & \\
\hline & Widowed & 11 & 9.3 & 5 & 7.0 & & & \\
\hline \multirow[t]{3}{*}{ Religion } & Protestant & 52 & 43.7 & 30 & 42.9 & 2.279 & 2 & 0.320 \\
\hline & Catholic & 51 & 42.5 & 25 & 35.7 & & & \\
\hline & Muslim & 16 & 13.3 & 15 & 21.4 & & & \\
\hline \multirow[t]{4}{*}{ Education } & None & 25 & 21 & 14 & 19.7 & 0.149 & 2 & 0.929 \\
\hline & $\begin{array}{l}\text { Primary school } \\
1-7 \text { year }\end{array}$ & 65 & 54.6 & 38 & 53.5 & & & \\
\hline & $\begin{array}{l}\text { Secondary school } \\
1-6 \text { year \& higher }\end{array}$ & 29 & 34.4 & 19 & 26.8 & & & \\
\hline & & \multicolumn{2}{|c|}{ Mean (SD) } & \multicolumn{2}{|c|}{ Mean (SD) } & $t$-test & $\mathrm{df}$ & $p$ \\
\hline \multicolumn{2}{|l|}{ Age } & \multicolumn{2}{|c|}{$38.4(12.16)$} & \multicolumn{2}{|c|}{$36.4(13.42)$} & 1.027 & 188 & 0.306 \\
\hline \multicolumn{2}{|c|}{ Education, number of years } & \multicolumn{2}{|c|}{$4.8(3.65)$} & \multicolumn{2}{|c|}{$5.2(3.77)$} & -0.720 & 188 & 0.472 \\
\hline
\end{tabular}


Attributions of Spirit Possession

Analysis of verbatim explanations of their complaints (open question SPQ-Ug) showed that $83 \%$ of the case group attributed their symptoms to cultural explanations (e.g., neglected cultural obligations and rituals, ancestral spirits, bewitchment) or sociocultural conflicts (e.g., disputes over unpaid dowries and land ownership). None of the case group spontaneously mentioned medical or psychological traumatic explanations and $13 \%$ did not mention any explanation.

\section{Spirit Possession and Dissociative Symptoms}

The possessed group reported a mean score of 2.78 ( $\mathrm{SD}=1.27$ ) on the CDS-Ug, whereas the control group did not recognize any symptoms and scored zero. In the case group the most common features according to the CDS-Ug were involuntary shaking of the head or parts of the body attributed to spirits $(67.2 \%)$, talking in a different voice that others recognized as the voice of a spirit $(62 \%)$, feeling influenced by unidentified forces that caused unusual behavior (referred to as Eibugane in Runyankore; 58\%) or feeling something holding the body so that one could not move or speak $(46.6 \%)$.

Compared to controls, patients with spirit possession reported more psychoform dissociative symptoms [DES; patients, $M=35.26, \quad \mathrm{SD}=11.54$; controls, $M=4.94, \mathrm{SD}=3.01 ; t(183)=21.22 ; p<0.0001]$, as well as more somatoform dissociative symptoms [SDQ-20; patients, $M=39.36, \quad \mathrm{SD}=7.38$; controls, $M=29.94, \mathrm{SD}=4.49 ; t(183)=14.087 ; p<0.0001)$.

\section{Spirit Possession and Potentially Traumatizing Events}

Individuals suffering from spirit possession reported more potentially traumatizing events than participants who were not possessed, on both the HTQ $[t(179)=15.05$; $p<0.0001]$ and the TEC $[t(176)=10.26, p<0.0001]$. Tables 2 and 3 show the differences in reported potentially traumatizing events between the possessed and the nonpossessed groups for all HTQ and TEC items. Particularly large differences between cases and controls were reported for items related to ill health, injury and life threats.

\section{Psychoform and Somatoform Dissociation and Reported Potentially}

Traumatizing Events

Correlations between the total scores of the questionnaires for the full sample $(n=190)$ are listed in Table 4. Strong correlations were found among culturally defined features of spirit possession, measures of psychoform and somatoform dissociation and reporting of potentially traumatizing events. Psychoform and somatoform dissociation were strongly correlated $(r=0.75, p<0.0001)$.

The CDS-Ug also was strongly correlated with the DES and SDQ ( $r=0.76$ and 0.68 , respectively). Studying DES and SDQ-20 as the dependent variables, there were main effects for the comparison between individuals with spirit possession and 
Table 2 Reported potentially traumatizing events on the HTQ by patients with spirit possession $(n=119)$ and controls $(n=71)$

\begin{tabular}{|c|c|c|c|c|}
\hline \multirow[t]{2}{*}{ Reported event(s) } & \multirow{2}{*}{$\begin{array}{l}\text { Spirit possession } \\
(\%)\end{array}$} & \multirow{2}{*}{$\begin{array}{l}\text { Controls } \\
(\%)\end{array}$} & \multicolumn{2}{|c|}{$\chi^{2}$ comparison } \\
\hline & & & $\chi^{2}(\mathrm{df}=1)$ & $p$ \\
\hline Lack of food or water & 25.2 & 5.6 & 11.60 & 0.001 \\
\hline Ill health, no access medical care & 33.6 & 7.0 & 17.37 & $<0.0001$ \\
\hline Lack of shelter & 4.2 & 2.8 & n.s. & \\
\hline Imprisonment & 5.0 & 12.7 & n.s. & \\
\hline Serious injury & 52.9 & 7.0 & 40.77 & $<0.0001$ \\
\hline Combat situation & 1.7 & 0.0 & n.s. & \\
\hline Brain washing & 3.4 & 0.0 & n.s. & \\
\hline Rape or sexual abuse & 2.5 & 0.0 & n.s. & \\
\hline Forced isolation & 12.6 & 0.0 & 9.71 & 0.002 \\
\hline Being close to death & 35.3 & 1.4 & 29.16 & $<0.0001$ \\
\hline Forced separation from family & 9.2 & 1.4 & F.E. & $0.008^{\mathrm{a}}$ \\
\hline Murder of family member/friend & 14.3 & 1.4 & 8.60 & 0.003 \\
\hline Unnatural death of family member & 31.9 & 1.4 & 25.40 & $<0.0001$ \\
\hline Murder of stranger & 19.3 & 0.0 & 15.61 & $<0.0001$ \\
\hline Lost or kidnapped & 8.5 & 0.0 & F.E. & $0.014(\mathrm{df}=1)$ \\
\hline Torture & 9.2 & 0.0 & F.E. & $0.028^{\mathrm{a}}$ \\
\hline Frightening life situation & 7.6 & 0.0 & F.E. & $0.028^{\mathrm{a}}$ \\
\hline
\end{tabular}

F.E. Fisher's Exact, two sided; this test was performed when at least one cell had an expected count $<5$ a $\alpha=0.05 / 17=0.003$

controls (MANOVA; Wilks' $\lambda F=177.51$, df $2, p<0.0001$ ) and for reported potentially traumatizing events as reported on the TEC $(F=4.50$, df 20 , $p<0.0001)$. An interaction between groups and reported potentially traumatizing events was not observed. Individuals with spirit possession had more psychoform and somatoform dissociation than nonpossessed individuals (DES, $F=315.40$, df $1, p<0.0001$; SDQ, $F=57.10$, df $1, p<0.0001$ ). Psychoform and somatoform dissociation in these groups were also associated with TEC scores (DES, $F=3.20$, df $10, p=0.001$; SDQ-20, $F=6.97$, df $10, p<0.0001)$. When the HTQ was used as a covariate, a main effect for group was also found $(F=118.74$, df 2 , $p<0.0001)$. However, there was a trend toward trauma reporting only on the HTQ $(F=1.63$, df $14, p=0.069)$, which seemed to be due to the DES ( $F=0.91$, df 7 , not significant) rather than the SDQ-20 $(F=2.82$, df $7, p=0.008)$.

\section{Discussion}

To our knowledge, this is the first quantitative study in an African context on the relationship among spirit possession, dissociative symptoms and reported potentially traumatizing events. 
Table 3 Potentially traumatizing events reported on the TEC by patients with spirit possession $(n=119)$ and controls $(n=71)$

\begin{tabular}{|c|c|c|c|c|}
\hline \multirow[t]{2}{*}{ Reported event(s) } & \multirow{2}{*}{$\begin{array}{l}\text { Spirit possession } \\
(\%)\end{array}$} & \multirow{2}{*}{$\begin{array}{l}\text { Controls } \\
(\%)\end{array}$} & \multicolumn{2}{|c|}{$\chi^{2}$ comparison } \\
\hline & & & $\chi^{2}(\mathrm{df}=1)$ & $p^{\mathrm{a}}$ \\
\hline Parentification & 23.5 & 5.6 & 10.17 & 0.001 \\
\hline Family burdens & 35.3 & 33.8 & n.s. & \\
\hline Death of family member in childhood & 84.9 & 46.5 & 31.54 & $<0.0001$ \\
\hline Death of own child/partner & 75.6 & 69.0 & n.s. & \\
\hline Severe physical injury & 45.4 & 4.2 & 35.86 & $<0.0001$ \\
\hline \multicolumn{5}{|l|}{ Life threat } \\
\hline Through illness, accident & 47.1 & 15.5 & 19.41 & $<0.0001$ \\
\hline Through person & 35.3 & 14.1 & 10.06 & 0.002 \\
\hline Intense pain & 22.7 & 7.0 & 7.77 & 0.005 \\
\hline War experiences & 36.1 & 8.5 & 17.81 & $<0.0001$ \\
\hline Observed trauma & 27.7 & 78.9 & 46.71 & $<0.0001$ \\
\hline \multicolumn{5}{|l|}{ Emotional neglect } \\
\hline Family of origin & 22.7 & 2.8 & 13.58 & $<0.0001$ \\
\hline Other family & 18.5 & 1.4 & 12.91 & $<0.0001$ \\
\hline Other & 19.3 & 2.8 & 10.61 & 0.001 \\
\hline \multicolumn{5}{|l|}{ Emotional abuse } \\
\hline Family of origin & 21.0 & 1.4 & 14.46 & $<0.0001$ \\
\hline Other family & 9.2 & 0.0 & F.E. & 0.008 \\
\hline Other & 10.1 & 0.0 & F.E. & 0.004 \\
\hline \multicolumn{5}{|l|}{ Physical abuse } \\
\hline Family of origin & 9.2 & 4.2 & n.s. & \\
\hline Other family & 1.7 & 0.0 & n.s. & \\
\hline Other & 4.2 & 0.0 & n.s. & \\
\hline
\end{tabular}

F.E. Fisher's Exact test, two sided; this test was performed when at least one cell had an expected count $<5$. Family of origin: by one or more members of the family of origin. Other family: by one or more other relatives. Other: by another person(s)

a $\alpha=0.05 / 19=0.0026$

Table 4 Pearson product-moment correlations among measures of dissociation and reported traumatizing events $(n=190)$

\begin{tabular}{lllll}
\hline & DES & SDQ-20 & CDS-Ug & TEC \\
\hline SDQ-20 & 0.75 & & & \\
CDS-Ug & 0.76 & 0.68 & & \\
TEC & 0.64 & 0.66 & 0.51 & \\
HTQ & 0.69 & 0.64 & 0.64 & 0.66 \\
\hline
\end{tabular}

All correlations significant at $p<0.0001$ (two tailed) 
We hope this study will contribute to a broader understanding of dissociation related to potentially traumatic experiences in different cultural contexts and how this can be manifested and understood as spirit possession, as an idiom of distress.

\section{Attributions of Spirit Possession}

In our study, spirit-possessed clients and their healers referred to sociocultural factors and not to potentially traumatizing events as explanations for their symptoms, which supported our first hypothesis. This corresponds with the explanations provided in focus groups for dissociative trance and possessive trance states during our qualitative research (Van Duijl et al. 2005). The focus groups explained the possessing agents as "spirits of the dead who speak though the living," usually manifesting themselves "because cultural rituals have not been performed," sometimes because obstruction by "the Christian generation," or "It can be a result of unresolved conflicts which the spirits try to settle." The fact that potentially traumatic experiences, such as mentioned in the HTQ, do not fit within these local explanations for spirit possession possibly underlies the fact that these traumatic experiences, although prevalent, are not spontaneously associated with spirit possession.

This is also illustrated by the case history in this paper in which the patient suffers from a possessing agent experienced as the spirit of her deceased uncle. This uncle had had a conflict with her Christian father, who refused to acknowledge and perform traditional rituals.

It was only after further probing that we understood that our patient, like her uncle, had a longstanding, unspoken, conflict with her father. She blamed him for her forced separation from her beloved child and husband. The Christian beliefs of her father and traditional role conceptions obstructed her happiness.

\section{Spirit Possession and Dissociative Symptoms}

The traditional healers' diagnosis of spirit possession was verified with a checklist of locally described dissociative symptoms, the CDS-Ug. It confirmed the distinction between the group suffering from spirit possession and the nonpossessed group. Frequently reported local symptoms of spirit possession included involuntary shaking of the head or parts of the body attributed to spirits, talking in a different voice, which others recognized as the voice of a spirit, and feeling influenced by unidentified forces, which caused behavior different from the usual behavior. These symptoms overlap with the DSM-IV research criteria for DTD (APA 1994). Nearly half of the possessed patients additionally mentioned something holding the body so that one could not move or speak. This symptom warrants further investigation for possible inclusion in the DSM-V criteria for DTD.

Our findings support the second hypothesis: that, compared to controls, patients with spirit possession report more psychoform and somatoform dissociative symptoms. Thus, next to the local presentation and clarification of this disorder, it is also associated with severe dissociation as defined and documented in Western 
countries. This is confirmed by the high correlations between the CDS-Ug and the DES as well as the SDQ (Table 4).

\section{Spirit Possession and Reported Potential Traumatic Events}

In support of the third hypothesis, patients with spirit possession reported more potentially traumatizing events than controls. They reported more cumulative potentially traumatizing events, on both the HTQ and TEC, as well as more events related to ill health, injury and near-death experiences (Tables 2, 3). A relationship between potentially traumatizing events and states attributed to spirit possession was also found by Van Ommeren et al. (2001), who, also using the HTQ, identified trauma, early loss and recent loss as predictors of attacks of medically unexplained illness in a Bhutanese refugee camp. This illness involved alterations of consciousness, which were culturally attributed to possession by spirits, rather than to traumatic experiences. As in our study, the Bhutanese patients scored higher on the SDQ-20 than the controls. Castillo (1994a, b) also suggested that trauma is a risk factor for spirit possession in South Asia. Therefore, there is evidence that the occurrence of spirit possession is related to traumatizing events and that patients of traditional healers may have experienced multiple traumatizing events.

\section{Dissociative Symptoms and Reported Traumatic Events}

The finding that psychoform and somatoform dissociation is associated with reported potentially traumatizing events (Table 4) confirms our fourth hypothesis and is in agreement with studies mentioned in the Background section in this paper on dissociation and trauma. Findings of this study suggest that bodily threat and threat to life related to other causes, such as severe illness and injury, may also contribute to the evocation of dissociative symptoms. Because correlational data cannot reveal causal relationships, the current findings do not demonstrate that potentially traumatizing events cause dissociation. However, they are in full consonance with prospective and longitudinal studies showing that events ranging from traffic accidents (Murray et al. 2002) to childhood abuse (Ogawa et al. 1997; Macfie et al. 2001) and traumatizing medical procedures (Diseth 2006) can induce short-term and long-term dissociative psychopathology.

\section{Some Methodological Constraints}

A limitation of this study is that the spirit-possessed respondents form a selected sample, as they first visited a traditional healer and subsequently were selected and referred for the study by these healers. Comparing local categories to Western classification systems is complicated because both systems are based on seemingly incompatible conceptualizations about causes and symptoms of distress. This also applies to our categorization of traumatic events, because it is possible that fear of ancestors, especially fear of witchcraft and sorcery, is locally perceived as a traumatic stressor. Despite these complications, an attempt to look for associations between common local presentations of distress and international classification 
systems seems necessary in countries where both systems are highly prevalent. Guarnaccia and Rogler (1999) mention two reasons for focusing research on cultural syndromes: the cultural diversity of persons seeking mental health care, also in Western countries, and the development of the DSM's becoming an internationally used document. The problem of the "category fallacy" (Kleinman 1988) is dealt with in this study by using local questionnaires (SPQ-Ug) and checklists (CDS-Ug) to explore the local features and explanations and to verify the local classification of spirit possession (Van Duijl et al. 2005). An additional constraint is that the SDQ-20, DES and TEC have not been validated in the East African context. However, high correlations between these questionnaires and the CDS-Ug and HTQ, respectively, support the convergent validity of these questionnaires.

Our findings on the relationship between dissociative symptoms and reported potentially traumatizing events gain perspective because there is no local cultural bias regarding an association between dissociative symptoms and trauma. Both traditional healers and their clients shared the local explanation that the possession was caused by "cultural" causes such as bewitchment, neglected rituals or angry ancestors and did not identify potentially traumatizing psychosocial events as related to spirit possession. It was only after explicit questioning that these experiences were confirmed. We therefore conclude that suggestion from the interviewer or from cultural sources does not explain trauma reporting of individuals with dissociative symptoms in Uganda. These findings cast doubt on the hypothesis that trauma reporting of individuals with dissociative symptoms would emerge from suggestion, as stated by Loftus (1993), Brown (1995) and Mair (1999). Neither secondary benefits nor knowledge about traumatic stress or DSMrelated symptoms play a role when reporting traumatic events as it might in Western countries (De Jong 2005).

\section{Implications for Clinical Practice}

It appears that spirit possession serves as an idiom of distress for the persons in this study who have experienced multiple psychological traumatizing events. This may provide them with a discourse that enables them to give meaning to their distress and find help within the locally available explanatory models and resources. These patients deserve attention with regard to the possible severity of dissociative symptoms and the relationship with having experienced potentially traumatizing events. Awareness of possibilities to classify pathological states of spirit possession as DTD can help to acknowledge the patient's perception of his or her illness and explore referral possibilities for treatment.

One should bear in mind, however, that spirit possession, both as part of an explanation or as a dissociative presentation, in itself is not pathological. Only when this, as an attribution or as a dissociative presentation, is causing clinically significant distress and impairment in social and occupational functioning can it be classified as a disorder. In our research we interviewed patients referred by healers, who had treated them, because of longstanding distressing and disabling symptoms. Even with the spirit-possessed patients in this research, one could argue whether the possessive state itself should be seen as pathological. For example, most of the 
patients before the healing ritual had been suffering from various somatic and dissociative complaints and had visited various health centers without finding relief. The actual possessed state occurred sometimes before, but also during, the healing ritual. The actual "appearance" of the possessing agents and possibilities for clarification and negotiation by the healer are part of the healing ritual (e.g., anger or grief can be part of exposure therapy). The spirits, called the emandwa (messengers) in the local context, give language and meaning to the experienced distress. The healers' ability to become possessed is part of the healing ritual (Seligman 2005).

This also does not imply that all spirit-possessed patients will need their traumatic experiences to be addressed in order to feel better. Remarkably, the vast majority of patients in our study group felt that the treatment by the traditional healer had helped them well (45\% felt better and 54\% completely healed after treatment).

Igreja (2003) describes how in Mozambique the recovery process of psychosocial hurts of war survivors seemed to be supported through the interaction of the Gamba spirits and healers that emerged after the war. De Jong (2002) also states that traditional healers and healing churches are often effective in dealing with the highly prevalent dissociative states in war-affected and low-income countries. In the first author's experience in southwestern Uganda, collaboration with traditional healers and mutual referral involving culturally sensitive counselors (Van Duijl 2003; Odenwald et al. 2007) effectively complemented government mental health services.

Implications for Classification of Spirit Possession

Pathological forms of spirit possession can be classified as a subtype of DTD, included in the DSM-IV Appendix on Criteria Sets for Further Study; the official body of the diagnostic manual includes pathological possession trance as an example of Dissociative Disorders Not Otherwise Specified. The ICD-10 (WHO 1992) similarly includes trance and possession disorders. DTD is defined by an involuntary state of trance that is not accepted as a normal part of a collective or cultural ritual. This state is accompanied by narrowing of awareness of immediate surroundings and stereotyped behavior or movement that one experiences as beyond one's control. In the subtype possession trance disorder, a single or episodic alteration in the state of consciousness is accompanied by the replacement of the customary sense of personal identity by a new identity that is attributed to the influence of a spirit, a power, a deity or another person (APA 1994). The stereotyped and culturally determined behaviors are experienced as being controlled by the possessing agent and there is full or partial amnesia for the event. The DSM IV concludes that when the trance or possession state is not accepted as a normal part of a collective cultural or religious practice and causes significant distress or impairment in functioning, it can be considered pathological.

The overlap of symptoms of spirit possession in Uganda with DSM-IV criteria demonstrates the clinical relevance of these phenomena. However, the inclusion of DTD in DSM IV has also been controversial because idioms of distress involving attribution to spirit possession can overlap several DSM diagnoses, for example, 
dissociative disorders, anxiety disorders and depression (APA 1995; Kirmayer 1996). Moreover, the local concepts regarding explanatory models and management can differ from the Western conceptualization of diagnostic categories in the DSM-IV (Bourguignon 1992; Kirmayer 1998; Lewis-Fernandez 1992). Another debate involves the question of what should be considered culturally sanctioned ceremonies and thus "normal" forms of spirit possession and what should be considered pathological dissociation (Antze 1992; Boddy 1992; Cardeña 1992; Cardeña et al. 2008; Koss-Chioino 1992; Leavitt 1993; Odenwald et al. 2007). As stated before, from a cultural perspective, possession trance is a common way of experiencing and describing dissociative phenomena (Cardeña 1996; Hollan 2000; Kirmayer 1998; Lewis-Fernandez 1998; Somer 2006).

\section{Implications for Further Research}

The impact of potentially traumatizing events related to war, poverty and societal disruption on the occurrence of dissociative and possessive trance disorders in developing countries deserves further research (Bracken et al. 1995). This also should include further research to evaluate the experimental criteria for DTD in different cultures and the question when the word pathological is appropriate in local contexts. Possible adaptations of presentations and symptoms of DTD associated with urbanization, societal change and migration will have to be taken into consideration. Finally, further development and evaluation of culturally sensitive treatment approaches that acknowledge the different cultural, religious and psychotherapeutic narratives and interventions are necessary.

Acknowledgments The authors thank Andrew Ainemugisha and Blanka Conze, research assistants, and Onno van der Hart, Ph.D., for suggestions in the initial stages of the research. We also thank the healers and patients for their trust, time and preparedness to collaborate in aid of this study. Furthermore, the first author is indebted to her (former) colleagues and employers at Mbarara University in Uganda, The Netherlands Embassy in Kampala, Lentis in Groningen and Center 45, Oegstgeest, in The Netherlands for supporting this research.

Open Access This article is distributed under the terms of the Creative Commons Attribution Noncommercial License which permits any noncommercial use, distribution, and reproduction in any medium, provided the original author(s) and source are credited.

\section{References}

American Psychiatric Association (APA)

1995 Diagnostic and Statistical Manual of Mental Disorders (DSM-IV). 4th Edition. Washington, DC: American Psychiatric Association.

Antze, P.

1992 Possession Trance and Multiple Personality: Psychiatric Disorders or Idioms of Distress? Transcultural Psychiatric Research Review 29: 319-323.

Behrend, H., and U. Luig

1999 Introduction in Spirit Possession, Modernity and Power in Africa (H. Behrend and U. Luig) Oxford: James Currey. 
Bernstein, E., and F.W. Putnam

1986 Development, Reliability, and Validity of a Dissociation Scale. Journal of Nervous and Mental Disease 102: 280-286.

Boddy, A.

1992 Comment on the Proposed DSM-IV Criteria of Trance and Possession Disorder. Transcultural Psychiatric Research Review 29: 323-330.

Boon, S., and N. Draijer

1995 Screening en diagnostiek van dissociatieve stoornissen [Screening and Assessment of Dissociative Disorders]. Lisse: Swets \& Zeitlinger.

Bourguignon, E., ed.

1973 Religion, Altered States of Consciousness, and Social Change. Columbus: Ohio State University Press.

Bourguignon, E.

1976 Possession. San Francisco, CA: Chandler \& Sharp.

1992 The DSM-IV and Cultural Diversity. Transcultural Psychiatric Research Review 29: 330-332.

Bracken, P.J., J.E. Giller, and D. Summerfield

1995 Psychological Responses to War and Atrocity: The Limitations of Current Concepts. Social Science and Medicine 40(8): 1073-1082.

Brown, P.

1995 Multiple Personality Disorder in the Netherlands: A Study on the Reliability and Validity of the Diagnosis, by S. Boon \& N. Draijer. Australian and New Zealand Journal of Psychiatry 29: 78-179; [Book Review].

Cardeña, E.

1992 Trance and Possession as Dissociative Disorders. Transcultural Psychiatric Research Review 29: 287-300.

1996 Dissociative Disorders: Phantoms of the Self. In Adult Psychopathology and Diagnosis. S.M. Turner and M. Hersen, eds., pp. 384-403. New York: Wiley.

Cardeña, E., M. van Duijl, L.A. Weiner, and B.A. Terhune

2008 Possession/Trance Phenomena. Chap. 11.3 in Dissociation and Dissociative Disorders: DSM V and Beyond New York: Routledge.

Carlson, E.B., F.W. Putnam, C.A. Ross, M. Torem, P. Coons, D.L. Dill, R.J. Loewenstein, and B.G.

Braun

1993 Validity of the Dissociative Experience Scale in Screening for Multiple Personality Disorder: A Multicenter Study. American Journal of Psychiatry 150: 1030-1036.

Castillo, R.J.

1992 Cultural Considerations for Trance and Possession Disorder in DSM-IV. Transcultural Psychiatric Review 29: 333-337.

1994a Spirit Possession in South Asia, Dissociation or Hysteria? Culture, Medicine, and Psychiatry 18: $1-21$.

1994b Spirit Possession in South Asia, Dissociation or Hysteria? Part 2: Case Histories. Culture, Medicine, and Psychiatry 18: 141-162.

1998 Culture and Dissociation. Meanings of Madness pp. 223-244. Pacific Grove, CA: Brooks Cole.

Chu, J.A., L.M. Frey, B.L. Ganzel, and J.A. Matthews

1999 Memories of Childhood Abuse: Dissociation, Amnesia, and Corroboration. American Journal of Psychiatry 156: 749-755.

Crescenzi, A., E. Ketzer, M. Van Ommeren, K. Phuntsok, I. Komproe, and J.T. de Jong

2002 Effect of Political Imprisonment and Trauma History on Recent Tibetan Refugees in India. Journal of Traumatic Stress 15(5): 369-375.

De Jong, J.T.

1987 A Descent into African Psychiatry. Amsterdam: Royal Tropical Institute.

2002 Public Mental Health, Traumatic Stress and Human Rights Violations in Low-Income Countries. In Trauma, War and Violence. Public Mental Health in Socio-Cultural Context. J.T. de Jong, ed. New York: Kluwer Academic/Plenum.

2004 Public Mental Health and Culture, Disasters as a Challenge to Western Mental Health Care Models, the Self, and PTSD. In Broken Spirits: The Treatment of Asylum Seekers and Refugees with PTSD. J.P. Wilson and B. Drozdek, eds., pp. 159-179. New York: Brunner/Routledge Press. 
2005 Deconstructing Critiques on the Internationalization of PTSD. Commentary. Culture, Medicine, and Psychiatry 29: 361-370.

De Jong, J.T., I.H. Komproe, and M. Van Ommeren

2003 Common Mental Disorders in Postconflict Settings. Lancet 361: 2128-2130.

De Jong, J.T., I.H. Komproe, M. Van Ommeren, M. El Masri, M. Araya, N. Khaled, W. Van de Put, and

D. Somasundaram

2001 Lifetime Events and Posttraumatic Stress Disorder in Four Postconflict Settings. JAMA 286(5): $555-562$.

Derluyn, I., E. Broekaert, G. Schuyten, and E. De Temmerman

2004 Post-Traumatic Stress in Former Ugandan Child Soldiers. Lancet 363: 861-863.

Diseth, T.H.

2006 Dissociation Following Traumatic Medical Treatment Procedures in Childhood: A Longitudinal Follow-up. Developmental Psychopathology 18: 233-251.

Freyd, J.J.

1996 Betrayal Trauma: The Logic of Forgetting Childhood Trauma. Cambridge, MA: Harvard University Press.

Frischholz, E.J., L.S. Lipman, B.G. Braun, and R.G. Sachs

1992 Psychopathology, Hypnotizability, and Dissociation. American Journal of Psychiatry 149: 15211525.

Guarnaccia, P.J., and L.H. Rogler

1999 Research on Culture-Bound Syndromes: New Directions. American Journal of Psychiatry 156(9): 1322-1327.

Hollan, D.

2000 Culture and Dissociation in Toraja. Transcultural Psychiatry 37(4): 545-559.

Igreja, V.

2003 "Why Are There So Many Drums Playing Until Dawn?” Exploring the Role of Gamba Spirits and Healers in the Post-War Recovery Period in Gorongosa, Central Mozambique. Transcultural Psychiatry 40(4): 459-487.

Kirmayer, L.J.

1996 Confusion of the Senses Implications of Ethnocultural Variations in Somatoform and Dissociative Disorders for PTSD. In Ethnocultural Aspects of Posttraumatic Stress Disorder. A.J. Marsella, M.J. Friedman, E.T. Gerrity, and R.M. Scurfield, eds., pp. 131-163. Washington, DC: American Psychological Association.

1998 The Fate of Culture in DSM-IV. Transcultural Psychiatry 35(3): 339-342.

Kleinman, A.

1988 What is a Psychiatric Diagnosis? In Rethinking Psychiatry. pp. 5-17. New York: Free Press.

Koss-Chioino, J.D.

1992 Possession/Trance and Psychopathology Mismatched Conceptual Constructs. Transcultural Psychiatric Research Review 29: 343-345.

Krug, E.G., L.L. Dahlberg, J.A. Mercy, A.B. Zwi, and R. Lozano, eds.

2002 World Report on Violence and Health. Geneva: WHO.

Leavitt, J.

1993 Are Trance and Possession Disorders? Transcultural Psychiatric Research Review 30: 51-57.

Lewis-Fernandez, R.

1992 The Proposed DSM-IV Trance and Possession Disorder Category: Potential Benefits and Risks. Transcultural Psychiatric Research Review 29: 301-317.

1998 A Cultural Critique of the DSM-IV Dissociative Disorders Section. Transcultural Psychiatry 35(3): 387-400.

Lewis-Fernández, R., A. Martínez-Taboas, V. Sar, S. Patel, and A. Boatin

2007 The Cross-Cultural Assessment of Dissociation. In The Cross-Cultural Assessment of Psychological Trauma and PTSD. J.P. Wilson and C. Tang, eds., pp. 279-317. New York:

Loftus, E.F. Springer.

1993 The Reality of Repressed Memories. American Psychologist 48: 518-537.

Lyons-Ruth, K., and D. Jacobovitz

1999 Attachment Disorganization: Unresolved Loss, Relational Violence, and Lapses in Behavioral 
and Attentional Strategies. In Handbook of Attachment: Theory, Research, and Clinical Applications. J. Cassidy and P.R. Shaver, eds., pp. 520-554. New York: Guilford.

Macfie, J., D. Cichetti, and S.L. Toth

2001 The Development of Dissociation in Maltreated Preschool-Aged Children. Development and Psychopathology 13: 233-254.

Mair, K.

1999 Development of a Dogma Multiple Personality. The Psychologist 12(2): 76-80.

Mollica, R.F., Y. Caspi-Yavin, P. Bollini, T. Truong, S. Tor, and J. Lavelle

1992 The Harvard Trauma Questionnaire Validating a Cross-Cultural Instrument for Measuring Torture, Trauma, And Posttraumatic Stress Disorder in Indochinese Refugees. Journal of Nervous and Mental Disease 180: 111-116.

Murray, J., A. Ehlers, and R.A. Mayou

2002 Dissociation and Post-Traumatic Stress Disorder: Two Prospective Studies of Road Traffic Accident Survivors. British Journal of Psychiatry 180: 363-368.

Musisi, S.

1998 The Psychological Consequences of War Traumatization on the Women of Luweero District. In The Short Term Intervention of the Psychological and Gynaecological Consequences of Armed Conflict in Luwero District (Uganda). Report. Kampala, Uganda: Isis-WICCE.

Nijenhuis, E.R.S., P. Spinhoven, R. Van Dyck, O. Van der Hart, and J. Vanderlinden

1996 The Development and the Psychometric Characteristics of the Somatoform Dissociation Questionnaire (SDQ-20). Journal of Nervous and Mental Disease 184: 688-694.

1998a The Psychometric Characteristics of the Somatoform Dissociation Questionnaire: A Replication Study. Psychotherapy \& Psychosomatics 67: 17-23.

1998c Degree of Somatoform and Psychological Dissociation in Dissociative Disorders Is Correlated with Reported Trauma. Journal of Traumatic Stress 11: 711-730.

1999 Evidence for Associations Between Somatoform Dissociation, Psychological Dissociation and Reported Trauma in Chronic Pelvic Pain Patients. In Somatoform Dissociation: Phenomena, Measurement, and Theoretical Issues. E.R.S. Nijenhuis, ed., pp. 146-160. Assen, Netherlands: Van Gorcum.

Nijenhuis, E.R.S., P. Spinhoven, J. Vanderlinden, R. Van Dyck, and O. Van der Hart

1998b Somatoform Dissociative Symptoms as Related to Animal Defensive Reactions to Predatory Threat and Injury. Journal of Abnormal Psychology 107: 63-73.

Nijenhuis, E.R.S., O. Van der Hart, and K. Kruger

2002 The Psychometric Characteristics of the Traumatic Experiences Questionnaire (TEC): First Findings Among Psychiatric Outpatients. Clinical Psychology and Psychotherapy 9(3): 200-210.

Nijenhuis, E.R.S., O. Van der Hart, K. Kruger, and K. Steele

2004 Somatoform Dissociation, Reported Abuse, and Animal Defence-Like Reactions. Australian and New Zealand Journal of Psychiatry 38: 678-686.

Ng, B.Y., and Y.H. Chan

2004 Psychosocial Stressors That Precipitate Dissociative Trance Disorder in Singapore. Australian and New Zealand Journal of Psychiatry 38(6): 426-432.

Norusis, M.J.

2002 SPSS 11.0 Guide to Data Analysis Upper Saddle River, NJ: Prentice-Hall.

O'Connel, M.C.

1982 Spirit Possession and Role Stress Among the Xesibe of Eastern Transkei. Ethnology 21: 21-37.

Odenwald, M., M. van Duijl, and T. Schmitt

2007 Disorders of Possession and Dissociation in the Intercultural Clinical Practice. In Culture and Mental Health: A Comprehensive Textbook. K. Bhui and D. Bhugra, eds., pp. 87-97. London: Hodder Arnold.

Ogawa, J.R., L.A. Sroufe, N.S. Weinfield, E.A. Carlson, and B. Egeland

1997 Development and the Fragmented Self: Longitudinal Study of Dissociative Symptomatology in a Nonclinical Sample. Developmental Psychopathology 9(4): 855-879.

Putnam, F.W.

1992 Multiple Personality Disorder. British Journal of Psychiatry 161: 415-416.

Sabin, M., B. Lopes Cardozo, L. Nackerud, R. Kaiser, and L. Varese

2003 Factors Associated with Poor Mental Health Among Guatemalan Refugees Living in Mexico 20 Years After Civil Conflict. JAMA 290(5): 635-642. 
Sar, V.

2006 The Scope of Dissociative Disorders: An International Perspective. Psychiatric Clinics of North America 29: 227-244.

Sar, V., T. Kundakci, E. Kiziltan, B. Bakim, and O. Bozkurt

2000 Differentiating Dissociative Disorders from Other Diagnostic Groups Through Somatoform Dissociation. Journal of Trauma and Dissociation 1(4): 67-80.

Seligman, R.

2005 Distress, Dissociation, and Embodied Experience: Reconsidering the Pathways to Mediumship and Mental Health. Ethos 33(1): 71-99.

Seligman, R., and L.J. Kirmayer

2008 Dissociative Experience and Cultural Neuroscience: Narrative, Metaphor, and Mechanism. Culture, Medicine, and Psychiatry 32(1): 31-64.

Somer, E.

2006 Culture-Bound Dissociation: A Comparative Analysis. Psychiatric Clinics of North America 29: 213-226.

Van der Kolk, B.A., D. Pelcovitz, S. Roth, F.S. Mandel, A. McFarlane, and J. Herman

1996 Dissociation, Somatization, and Affect Dysregulation: The Complexity of Adaptation to Trauma. American Journal of Psychiatry (Festschr. Suppl.) 153: 83-93.

Van Duijl, M.

2003 Culturally Sensitive Counselling in Uganda. Memisa Medisch 69: 18-27.

Van Duijl, M., E. Cardeña, and J. de Jong

2005 The Validity of DSM-IV Dissociative Disorders Categories in Southwest Uganda. Transcultural Psychiatry 42(2): 219-241.

Van Ommeren, M., B. Sharma, I. Komproe, B.N. Poudyal, G.K. Sharma, E. Cardena, and J.T.V.M. de Jong

2001 Trauma and Loss as Determinants of Medically Unexplained Epidemic Illness in a Bhutanese Refugee Camp. Psychological Medicine 31(7): 1259-1267.

Van Ommeren, M., B. Sharma, G.K. Sharma, J.T.V.M. de Jong, I. Komproe, and E. Cardeña

2003 The Relationship Between Somatic and PTSD Symptoms Among Bhutanese Refugee Torture Survivors. In The Impact of War Trauma on Civilian Populations: An International Perspective. Trauma and Dissociation. T.M. McIntyre and S. Krippner, eds., Vol. 1, pp. 81-98. Santa Barbara, CA: Greenwood Press/Praeger.

Vinck, P., P. Pham, E. Stover, and H. Weinstein

2007 Exposure to War Crimes and Implications for Peace Building in Northern Uganda. JAMA 298(5): 543-554.

Ward, C.

1980 Spirit Possession and Mental Health: A Psycho-Anthropological Perspective. Human Relations 33(3): 149-163.

Welbourn, F.B.

1964 The Idea of a High God in Three East African Societies. Institute of African Studies, University of Ife. http://people.ucalgary.ca/ nurelweb/papers/fred/highgod.html.

World Health Organization

1992 International Statistical Classification of Diseases and Related Health Problems, 1989 Revision. Geneva: WHO.

World Medical Assembly

1997 Declaration of Helsinki: Recommendations Guiding Physicians in Biomedical Research Involving Human Subjects. JAMA 277: 925-926. 